\title{
A qualitative exploration of the motivations underlying anabolic-androgenic steroid use from adolescence into adulthood
}

\section{BACKGROUND}

This study explored the direct experience of anabolic androgenic steroid (AAS) use by young men, with an emphasis on how motivations progressed from adolescent initiation to more entrenched usage.

\section{PARTICIPANTS AND PROCEDURE}

Nine semi-structured interviews were conducted with individuals ranging in experience of AAS use, from novice to experienced users.

RESULTS

The results indicated that the young adult men progressed through a clear transition whereby their motives for using

\begin{abstract}
these substances changed from a mere desire to compete with other men to more internalised body image problems.

\section{CONCLUSIONS}

The findings presented suggest a more complex relationship between AAS use and body image pathology than previously suggested.
\end{abstract}

\section{KEY WORDS}

body image; anabolic steroids; adolescent substance use; risk-taking behaviours

ORGANIZATION - Cardiff Metropolitan University, United Kingdom

aUthors' contributions - A: Study design - B: Data collection - C: Statistical analysis - D: Data interpretation .

E: Manuscript preparation · F: Literature search · G: Funds collection

CORRESPONDing AUtHOR - Marc Ashley Harris, Llandaff Campus, Cardiff Metropolitan University, Western Avenue,

Cardiff CF5 2YB, United Kingdom, e-mail: marcashleyharris@yahoo.com 


\section{BACKGROUND}

Anabolic androgenic steroid (AAS) use is rapidly becoming a contemporary public health problem for many western countries. The British Medical Association Board of Science and Education (2002) revealed prevalence in UK fitness centres to be around $13 \%$, whereas in dedicated bodybuilding gyms the prevalence rate peaks at almost one half of all members. This growth in AAS usage is supported by a $2000 \%$
Marc Ashley Harris,

Michael Dunn, Tina Alwyn increase in needle exchange attendance from 19912006 (Hoare \& Flatley, 2008). Dandoy and Greige (2012) have shown that $3.30 \%$ of $9^{\text {th }}-12^{\text {th }}$ grade students in the US reported having used AAS in the past. Investigations in Canadian, Brazilian, South African and Swedish populations also confirm a cross cultural prevalence rate of between 1-3\% (Adlaf \& Smart, 1992; Galduroz, Noto, Nappo, \& Carlini, 2005; Lambert, Titlestad, \& Schwellnus, 1998; Kindlundh, Isacson, Berglund, \& Nyberg, 1999, respectively). The most accurate estimate for prevalence within the UK general population has identified 293,000 people having used AAS in their lifetime, with 73,000 people having used in the past year (Crime Survey for England \& Wales, 2015).

The use of these misunderstood substances has added depth when the mental and physical side effects are considered. For example, Angell et al. (2012) explains case study evidence of a link between AAS use and cardio vascular disease (e.g. myocardial infarction), which is highly supported by Pope et al. (2013) with the addition of psychiatric and endocrine disorders. Also, Baggish et al. (2010) emphasised the risk of heart failure in long term users to be more severe than previously thought. The increasing use of anabolic steroids combined with a perception of limited risk in users (see Kimergård \& McVeigh, 2014) therefore presents a public health issue in a state of severe incline. With the above in mind, the current study aimed to explore the reasons young males initiated AAS use and also their motives towards continued use.

Two distinct theories have been associated with the use of AAS, the conduct problem explanation which associated use solely with adolescent antisocial behaviour and risk-taking behaviours, and the muscle dysmorphia interpretation which argues AAS use as representing distorted body image. Miller, Barnes, Sabo, Melnick, and Farrell (2002) rejected the argument for AAS being a mere drive for the male athletic ideal, as its usage had a strong relationship with other high risk behaviours (e.g. multiple drug use or suicide attempt). The authors argued that AAS use represents a pattern of risk taking behaviours, rather than an independent problem. Further, Nilsson, Baigi, Marklund, and Fridlund (2001) provided strong evidence for pat- terned, multiple drug use, which excluded cannabis and tobacco (Dodge \& Hoagland, 2011). Kanayama, Hudson, and Pope (2010) introduced biological evidence for this association, explaining that both human and animal research indicates both AAS and other illicit drugs involve similar brain structures and mechanisms. Adopting a similar theoretical position to Miller, Barnes, Sabo, Melnick, and Farrell (2002), Wichstrøm and Pederson (2001) proposed that AAS use reflects only an alternative form of problem behaviour with only a secondary association with sport. Thiblin and Pärlklo (2002) strengthen this argument with the discovery that AAS use prospectively increased the risk of an antisocial lifestyle, whereas Kanayama, Pope, Cohane, and Hudson (2003) add that illicit drug use almost always precedes AAS use. In a review of recent findings Harmer (2010) highlight a wealth of recent evidence promoting the idea that AAS use rather than being focussed on muscularity and/or athletic endeavours, is part of a broader syndrome of problem behaviour, expanding that efforts to reduce rates of usage should focus on the general adolescent population as opposed to athletes.

The literature and media dominant explanation for AAS use adopts the position that individuals use such substances as a result of psychological anxiety which stems from an underlying body image disorder. This explanation is the product of studies revealing AAS users to be substantially less confident and satisfied with their body image than non-users, which is further fuelled by bodybuilding (Kananyama et al., 2003; Olivardia, Pope, Borowiecki, \& Cohane, 2004; Blouin \& Goldfield, 1995). Pope, Gruber, Choi, Olivardia, and Phillips (1997) categorised the symptomatic expression of such feelings with the term muscle dysmorphia (MD) whereby people become pre-occupied by their degree of muscularity, and reverse anorexia (RA) which is characterised by a feeling of inadequate and reduced muscularity as muscularity actually increases significantly (Pope, Katz, \& Hudson, 1993). In support of this causal explanation, Kanayama et al. (2003) highlighted that users differed significantly from non-users on symptoms of MD, whilst Kanayama, Barry, Hudson, and Pope (2006) posited that body image pathology is prominent in men with long term AAS use. Interestingly, Pope, Kanayama, and Hudson (2012) discovered that whilst many attributes showed little association to AAS use, intense body image concerns and conduct problems showed strong associations.

The current body of evidence on the subject of AAS use promotes a highly disjointed understanding as to why it occurs so abundantly. There have been key evidence-based explanations which are, at a superficial level at least, linked to its use however the causal direction of each remains contested. Further to this, they are approached by a majority 
of researchers as separate entities with a narrow, rejecting viewpoint on the interaction of each. The purpose of the current study is to delineate both the potential precursors of AAS use and to highlight the contributions of different factors pertinent to its continued and prolonged usage.

\section{PARTICIPANTS AND PROCEDURE}

The research was conducted to investigate the reasons young adult males report for both beginning and continuing AAS use. To enable the exploration of experiences and behaviours surrounding AAS use and to examine the co-occurrence of problem behaviours and body image concerns, in-depth interviews were conducted with nine young adult males with an age range of 18-28. Opportunistic sampling was utilised whereby participants were selected from two body-building dedicated gymnasiums in Wales, one rural based and one city based. The owners of both gyms were informed about the aims of the current study and agreed to facilitate by informing gym members of its objectives and requirements, including having previously used AASs. The owners provided a quiet room for the interviews to take place and an appropriate time and date was agreed between the lead researcher and each participant. The lead researcher conducted all 9 semi-structured interviews using an identical interview schedule based on questions developed from the literature discussed above. A clear attempt was made to reduce social desirability bias by conducting the interviews within this comfortable environment for the participants, and by having the gym owners inform the participants of the research, the interview process, the basis of the interview questions and the focus on AAS prior to informed consent being taken.

Critical to the objectives outlined above, and within a qualitative framework, 9 semi-structured interviews were conducted to gain preliminary insight into the perceptions held by users of why they initiated AAS use and why they continued to use. A semi-structured interview schedule was developed and piloted and detailed interviews were conducted ranging from 30 to $50 \mathrm{~min}$. The intention was to facilitate both the ease and the participant's willingness to discuss the sensitive issues covered. Interviewing provided a necessary means of exploring how problem behaviours and body image concerns initiated and developed with AAS use, gaining insight into the causal or perpetuating nature of each. The interview schedule reflected this objective focussing on experiences surrounding AAS use initiation and current motives for such usage, with an emphasis on transition. The interviews were audio recorded and transcribed following each, and were collectively an- alysed using thematic analysis (see Braun \& Clarke, 2006). To ensure the reliability of the findings the transcripts of each interview were checked independently by the third author against the results of the thematic analysis.

\section{RESULTS}

\section{MOTIVE TRANSITION}

The interview transcripts revealed that users perceived themselves to have passed through a clear transition, whereby their motives for using AAS changed from the external motivation of merely competing with other men, to a deeply internal need to mediate body image concerns.

"Pressure from PE teachers to bulk out... obviously when your younger you want to do it mainly to get the girls... because you wanna look a bit bigger, and... like peer pressure, like if you see quite a lot of your friends going to the gym, you don't wanna feel as if they are going to get bigger than you... then the more you train the more obsessed you get, and you look at certain parts of your body and you think I need to improve... and obviously certain parts of your body will grow quicker than others but then I think I just wanted the steroids to bulk out the areas where I felt as if I was looking weak and I was feeling weak".

(Callum, aged 20, 2 years' usage experience)

The motives for bodybuilding itself changed dramatically from a combined sport and aesthetic desire to improve, to a purely aesthetic need to improve. It was this nurtured need that exhibited strong influence upon a motivation to use AAS.

"I got the gear in ready before I started training... I wanted to build the muscle up and then start taking roids... I seen some boys from school... and all of a sudden they're looking awesome, they've got a lot of shape, a lot of mass, they look healthier, so then straight away I thought I'm up for a bit of that, found out where I can get some roids from, started training and so on from there... [now] just enjoy the results I get off it, better gains... feel better in myself... I've always done it it's just my way".

(Lewis, aged 22, 4 years' experience)

It would appear that the internal desire to compete aesthetically with other males is a strong driving force which influences a decision to take AAS, however over time the external motives to impress other people becomes internalised into a powerful need for self-satisfaction, with the use of AAS becoming normalised.

"[Started training for] a vanity thing... looking big... for about 6 months, when I was 18 and... there was a bloke... and he is fucking massive, so I asked him is there things? [steroids], because everyone wanna quick gain like... [now] your so used to get-
Anabolic steroid use by young men 
ting the gains, you don't wanna stop because your still the wrong way round, still not happy with how I look, and never will be".

(Rhys, aged 28, 9 years' experience)

During the early stages of bodybuilding the [more relaxed] attitudes towards building muscularity at an increased rate fuel a desire to take substances as a means of achieving such objectives, however over time this subtler approach is met with an increased need to take AAS to fuel far greater internal motivations of gaining muscularity.

"People I knew where on them and I sort of said to myself if I bought them I would get serious about my training... people around me in uni were in good shape and trained a lot and ate well, and I just thought oh well everyone else is doing it... I don't think about them all the time but now that I know how to access them, how to use them I just wanna go heavier, like the next cycle I do".

(Corey, aged 21, 1-year experience)

Here from the perspective of a new user of AAS, at the initiation phase, the relaxed attitudes towards use are reinforced, which are reinforced by competing with other people aesthetically, although there are early signs of increased reliance upon them with a desire to use greater amounts.

\section{BODY IMAGE PATHOLOGY}

The data reveals intense feelings towards own body image to be central to AAS use and bodybuilding in general. However, the relationship between both was a complex interaction which manifests over a period of time for the individuals interviewed.

“...You look in the mirror it just doesn't seem like anything is happening... [Before] I didn't really think about it... happy with myself, and then... I just wanted more and more... like oh I'll do this now [steroids] and it'll make me a lot bigger... everybody else wants to be big don't they, and be bigger than each other".

(Chris, aged 20, 3 years' experience)

It is evident that the early stages of a body image problem are being exhibited. There is a definite personal position held on the importance of challenging others aesthetically. Moreover, there is a transition from being content with personal appearance to a strong feeling of muscular inadequacy.

"[Steroids] easy to get, all the boys were on it, they were all getting bigger than me... [now] Just all in your head... you see other boys getting bigger than you and you just go back on it... just looking at everyone else in the gym getting bigger and I feel like I'm stuck in the same place".

(Adam, aged 25, 7 years' experience)

The expression of a body image problem reveals a more competitive element here, there is higher emphasis on matching or overtaking other's measures of muscularity, which also appears to have become more intense from initiation to now.

"...Everytime you look in the mirror you think there's nothing there but your not seeing what other people are seeing, even now you know I've trained for years, people saying well fucking hell you're in good shape... you think well I look fucking terrible, I look small... you drink fucking bleach if someone said it put fucking two stone on you... [Before] I felt small but it didn't affect me, didn't really bother me... [now] hell it's like 4 stone difference and still feel small”.

(Rhys, aged 28, 9 years' experience)

The intensity of negativity felt towards being under a degree of desired muscularity is greatly expressed here. There is a clear problematic thought-process and a direct 'achieve at all costs' mentality.

"One little comment... like 'you've lost a bit of weight' my head will go and I'll go home and feel like I wanna have a jab..., I'm knackered from it, I started dieting and that as well now, and if I eat chocolate and things like that it will blow my head".

(Lewis, aged 22, 4 years' experience)

Such negative intense feelings are reinforced here with an experienced user of AAS, whilst also mentioning AAS as a means of escaping such negative emotional responses.

\section{RISK/PROBLEM BEHAVIOURS}

Evidence from the data revealed other risky behaviours to also run alongside AAS use, although the relationship was particularly evident during the initial stages of AAS use and relatively absent in consideration during the later stages of usage.

"I've done MDMA and coke mainly before... when there's a big festival or I'm going to see a big act... I've drunk drove a couple of times and I don't use a condom"

(Michael, aged 20, 1-year experience)

The uses of other illicit drugs are prominent and also feature a planned element, identical to AAS. Moreover, other high risk behaviours of drink-driving and un-protective sex are also mentioned.

"Party drugs really... Cocaine, MDMA... [since] months... [and]... fighting... on a night out".

(James, aged 18, 1-year experience)

The reported new experiences of other illicit drugs also mirror the initiation of AAS, whilst also displaying the problematic behaviour of fighting.

"I'm a frequent drug user, I like a bit of cocaine now and again, when I was younger I was a lot worse... when I was about $15 . .$. and I started on amphetamine and things like that, and then meow come out and I went on to that... I've done drink driving... I was just like that anyway".

(Lewis, aged 22, 4 years' experience) 
Here an experienced user of AAS also reports experiences of widespread use of other illicit drugs and high risk behaviour, however isolates the extent of these in the past tense, whilst highlighting a reduction overtime.

\section{DISCUSSION}

The analysis revealed body image pathology and problem behaviours to be highly associated with AAS use. Body image pathology was discovered to play an overwhelming role in the expression of AAS use, however the relationship is far more complex than previously assumed by current literature (cf. Pope et al., 2012). Supporting previous findings suggestive of an association between AAS use and body image problems (cf. Kanayama 2003; Kanayama et al., 2006), the current research highlighted the existence of a transitional period whereby AAS use and bodybuilding fuelled the expression of a body image problem, rather than a body image problem precipitating AAS use. The in-depth interviews exposed experiences and explanations behind AAS use to be lacking the emotional significance to be appropriately regarded as a body image problem during a decision to initiate AAS use. It was over-time that intense pressure on gaining muscularity began to manifest itself into a problematic pattern of body image concerns, which may not necessarily reflect a consequence of AAS but rather a bi-product of the competitive nature of bodybuilding within the environment of a dedicated bodybuilding gymnasium. Therefore, the current literature adds to the classic study of Pope et al. (1997) and Olivardia et al. (2004) in that rather than muscle dysmorphia or reverse anorexia causing AAS use, it functions to perpetuate its usage, whilst also being a consequence of bodybuilding and usage itself, thus also portraying a circular maintenance pattern of addictive behaviour.

The nine detailed interviews also revealed other problematic behaviours to be present during AAS use. This discovery from a qualitative perspective provides further evidence for previous findings proposing that AAS use is associated with other high risk behaviours such as fighting, sexually risky behaviour and illicit drug use from a quantitative perspective (Miller et al., 2002; Nilsson, Baigi, Marklund, \& Fridlund, 2001; Wichstrøm \& Pederson, 2001). However, the current study's findings strongly contradict the standpoint of Harmer (2010) claiming AAS use to be part of a broader range of problem behaviours and only secondarily associated with muscularity, at least the oversimplified argument presented. The data revealed a pattern of problem behaviours to be highly prominent during the initiation of AAS use, possibly reflecting an increased feeling of invulnerability, whereas such patterns of behaviour were reported as being significantly less prominent during the later stages of AAS use, when bodybuilding itself becomes more intrinsically rewarding. The research therefore provides evidence that an explanation based on problematic behaviours may have greater strength in explaining the initiation of AAS use rather than its maintenance.

\section{CONCLUSIONS}

The current qualitative research was limited to a sample of nine young adult males therefore the conclusions made are to be treated as explorative only. However, the responses gathered provide a compelling argument that AAS use reflects a typically adolescent pattern of overall problem behaviours during initiation, however a later developed body image problem results in the perpetuation of the use and reliance upon such substances, whereby an explanation based on problem behaviours becomes substantially less able to explain the pattern of planned substance use/abuse. The explorative findings gathered here highlight a more complex relationship between body image and AAS use than previously suggested. The extent to which body image problems initiate or perpetuate the use of these substances warrants further examination.

\section{REFERENCES}

Adlaf, E. M., \& Smart, R. G. (1992). Characteristics of steroid users in an adolescent school population. Journal of Alcohol and Drug Education, 38, 43-49.

Angell, M. P., Chester, N., Green, D., Somauroo, J., Whyte, G., \& George, K. (2012). Anabolic steroids and cardiovascular risk. Sports Medicine, 42, 119134. doi: 10.2165/11598060-000000000-00000

Baggish, A. L., Weiner, R. B., Kanayama, G., Hudson, J. I., Picard, M. H., Hutter, A. M., \& Pope, H. G. (2010). Long term anabolic-androgenic steroid use is associated with left ventricular dysfunction. Circulation: Heart Failure, 3, 472-476. doi: 10.1161/ CIRCHEARTFAILURE.109.931063

Blouin, A. G., \& Goldfield, M. A. (1995). Body image and steroid use in male bodybuilders. International Journal of Eating Disorders, 18, 159-165. doi: 10.1002/1098-108X(199509)18:2<159::AID-EAT 2260180208>3.0.CO;2-3

Braun, V., \& Clarke, V. (2006). Using thematic analysis in psychology. Qualitative Research in Psychology, 3, 77-101. doi: 10.1191/1478088706qp063oa

British Medical Association Board of Science and Education. (2002). Drugs in Sport: The Pressure to Perform. London: BMA.

Crime Survey for England and Wales. (2015). Drug Misuse [online]. Available from: https://www.gov.
Anabolic steroid use by young men 
Marc Ashley

Harris,

Michael Dunn, Tina Alwyn uk/government/uploads/system/uploads/attachment_data/file/462885/drug-misuse-1415.pdf [Accessed on $11^{\text {th }}$ July 2016].

Dandoy, C., \& Gereige, R. S. (2012). Performanceenhancing drugs. Paediatrics in Review, 33, 265272. doi: 10.1542/pir.33-6-265

Dodge, T., \& Hoagland, M. F. (2011). The use of anabolic androgenic steroids and polypharmacy: A review of the literature. Drug and Alcohol Dependence, 114, 100-109. doi: 10.1016/j.drugalcdep.2010.11.011

Galduroz, J. C., Noto, A. R., Nappo, S. A., \& Carlini, E. A. (2005). Household survey on drug abuse in Brazil: study involving the 107 major cities of the country. Journal of Addictive Behaviours, 30, 545-556. doi: 10.1016/j.addbeh.2004.08.004

Harmer, P. A. (2010). Anabolic-androgenic steroid use among young male and female athletes: is the game to blame? British Journal of Sports Medicine, 44, 26-31. doi: 10.1136/bjsm.2009.068924

Hoare, J., \& Flatley, J. (2008). Drug misuse declared: Findings from the 2007/2008 British Crime Survey England and Wales. London: Home Office.

Kanayama, G., Barry, S., Hudson, J. I., \& Pope, H. G. (2006). Body image and attitudes toward male roles in anabolic-androgenic steroid users. American Journal of Psychiatry, 163, 697-703.

Kanayama, G., Hudson, J. I., \& Pope, H. G. (2010). Illicit anabolic-androgenic steroid use. Hormones and Behaviour, 58, 111-121. doi: 10.1016/j.yhbeh.2009.09.006

Kanayama, G., Pope, H. G., Cohane, G., \& Hudson, J. I. (2003). Risk factors for anabolic-androgenic steroid use among weightlifters: a case-control study. Drug and Alcohol Dependence, 71, 77-86. doi: 10.1016/S0376-8716(03)00069-3

Kimergård, A., \& McVeigh, J. (2014). Environments, risk and health harms: a qualitative investigation into the illicit use of anabolic steroids among people using harm reduction services in the UK. BMJ Open, 4, e005275. doi: 10.1136/bmjopen2014-005275

Kindlundh, A., Isacson, D., Berglund, L., \& Nyberg, F. (1999). Factors associated with adolescent use of doping agents: anabolic-androgenic steroids. Addiction, 94, 543-553. doi: 10.1046/j.13600443.1999.9445439.x

Lambert, M. I., Titlestad, S. D., \& Schwellnus, M. P. (1998). Prevalence of androgenic-anabolic steroid use in adolescents in two regions of South Africa. Journal of South African Medicine, 88, 876-880.

Miller, K. E., Barnes, G. M., Sabo, D. F., Melnick, M. J., \& Farrell, M. P. (2002). Anabolic-androgenic steroid use and other adolescent problem behaviors: Rethinking the male athlete assumption. Sociological Perspectives, 45, 467-489. doi: 10.1525/sop. 2002.45.4.467
Nilsson, S., Baigi, A., Marklund, B., \& Fridlund, B. (2001). The prevalence of the use of androgenic anabolic steroids by adolescents in a county of Sweden. Public Health, 11, 195-197.

Olivardia, R., Pope, H. G., Borowiecki, J. J., \& Cohane, G. H. (2004). Biceps and body image: The relationship between muscularity and self-esteem, depression and eating disorder symptoms. Psychology of Men and Masculinity, 5, 112-120. doi: 10.1037/1524-9220.5.2.112

Pope Jr, H. G., Wood, R. I., Rogol, A., Nyberg, F., Bowers, L., \& Bhasin, S. (2013). Adverse health consequences of performance-enhancing drugs: An Endocrine Society scientific statement. Endocrine Reviews, 35, 341-375. doi: 10.1210/er.2013-1058

Pope, H. G., Gruber, A. J., Choi, P., Olivardia, R., \& Phillips, K. A. (1997). Muscle dysmorphia: An under recognised form of body dysmorphic disorder. Psychosomatics, 38, 548-557.

Pope, H. G., Kanayama, G., \& Hudson, J. I. (2012). Risk factors for illicit anabolic-androgenic steroid use in male weightlifters: a cross-sectional cohort study. Biological Psychiatry, 71, 254-261. doi: 10.1016/j.biopsych.2011.06.024

Pope, H. G., Katz, D. L., \& Hudson, J. I. (1993). Anorexia nervosa and "reverse anorexia" among 108 male bodybuilders. Comprehensive Psychiatry, 34, 406-409. doi: 10.1016/0010-440X(93)90066-D

Thiblin, I., \& Pärlklo, T. (2002). Anabolic androgenic steroids and violence. Acta Psychiatrica Scandinavica, 106, 125-128. doi: 10.1034/j.1600-0447.106. s412.27.x

Wichstrøm, L., \& Pedersen, W. (2001). Use of anabolicandrogenic steroids in adolescence: winning, looking good or being bad? Alcohol and Drugs, 62, 5-13. 